\title{
MANAGING THE CHALLENGES OF INCORPORATING NEW DIGITAL TECHNOLOGY IN PUBLIC BROADCASTING Services in Brazil and Portugal
}

\author{
Carlos Eduardo Esch \& Mariana Martins de Carvalho
}

\begin{abstract}
Digital technology and the rise of innovative online communication services are defining a challenging context for communication medium managers in general and in particular for those who administer public broadcasting systems. This context has propelled these professionals to come up with and establish a set of actions for shaping strategies so that these institutions can produce, advertise and offer media content across new platforms, and thereby re-establish and renew their consumer ties with certain audience profiles. A scene which has been shaped by the ever increasing virtual media options available to users which has led public communication mediums to lose parts of their audience, a situation which, in special circumstances, could threaten the social legitimacy of this particular broadcaster, its actual commitment to its mission and relegate it to a less-important level in the eyes of its citizens. This paper analyzes the challenges public broadcasting services in Brazil and Portugal have incorporating new technology and making themselves visible to an online public.
\end{abstract}

Keywords

Public broadcasting; management; digitalization; convergence and online communication

\section{A CONTEXT FOR CHANGE}

The existing public broadcasting systems in Latin America and Europe are going through a historic period marked by challenges of huge changes within their respective national scenes. Over the last couple of decades, the list of transformations has included regulatory policies for financing each national context and reached strategies that are being adopted to face the challenges that digital technology and the expanding world of online communication poses to everyone (Arons de Carvalho, 2009).

Over the last twenty years there has been a proliferation of platform and technology distribution, like digital television, IPTV (Internet television), mobile television and video on demand. Competition has increased significantly with the arrival of new operators in the market, like internet companies. Advances in technology have also led to new online and on demand services in communication, information and entertainment.

There is a tendency for audiovisual services to converge within this complex scene of changes, providing consumers with an increasing number of services across different virtual platforms and mobile devices. The emergence of multiple audiovisual services led audiences from so-called conventional media to naturally dissipate.

While this is happening, traditional use of media - to a large extent passive - is gradually giving way to another more active form of participation with a greater control 
over content that users wish to access. In this environment of transformation, managers of public broadcasting companies search for diversified forms of delivering content to new distribution platforms, thereby increasing the chances of consumption provided by the omnipresent TV (Serra, 2015). In order to do this, managers have to decipher and understand the dynamics of the agile and changing "virtual ecosystem" and its services, networks and users.

As a result, confronting innovative technologies and their consequences is a common and basic challenge for all broadcasting services, especially for public ones both in Europe and Latin America, and in particular, Brazil and Portugal. For Europe, successfully addressing these technologies could mean reinventing public radio and renewing social ties of belonging and identity (Wolton, 2006). For Brazil, it could be a tool for overcoming, to some degree, the massive invisibility that public radio still suffers in society. Innovation and its ability to reach out and capture a younger public makes the virtual space a powerful tool for advertising public mediums to audiences who currently do not think of TV or public radio as part of their media menu.

Public media managers who successfully face this new technology and its demands and possibilities are extremely important when we consider the importance that public broadcasting can attain on a national level. Despite the relative economic value inherent to it, theoretically it cannot be compared to any other type of service provided by any other state. Its very nature means it offers diverse, plural, distinct and universal information and content able to guide and influence public opinion (Unesco, 2001). However, in order for public broadcasting entities to operate in the new scene, their managers need to rethink and retool their operations.

\section{THE MAJOR CHALLENGE: SPREADING CONTENT ACROSS THE NETWORK}

We are at a moment in history when a set of social and cultural practices, and the innovative digital technology that has grown around them, make up what is known as network culture (Jenkins, Green \& Ford, 2014). These practices did not come about only through technological development. The facts around the events have always generated interest and promoted discussion among people over the course of time. However, the circulation of content nowadays, in a world which is heavily dependent on virtual communication and increasingly rooted in digital technology, is much different than other forms from the past, including analogue. The contemporary trademark of communication has become the quickness, the range and the speed of information, many of which are used for the rapidly growing tools for online social contact nowadays.

Reflecting on these changing circumstances is important, and most importantly, strategic. After all, networks that connect computers, people and institutions together across the world generate a unique environment in which new ways of experiencing diverse relations of an institutional and personal nature are repeatedly established every day. This ends up creating a profoundly dynamic scene given the clear transformation occurring in forms of relationships and consumption. Media content is not only transmitted 
by traditional means anymore, in other words, through electromagnetic waves and radio broadcasts focused on production and business.

The development of digital technology has allowed people to interact across many social tools available on the internet. Thus, the process of communication has been strengthened by the quantity and reach of messages circulating in a real-life web of intercommunicating channels. Content goes through many alterations within this intense process as countless numbers of users distribute or redistribute their feelings, ideas, values, affection, rejections and interests. This trafficking of messages leads towards giving content new meaning for network users whether individuals, groups, movements or institutions. This is a fundamental change which means thinking realistically about the new virtual world in which media content is distributed nowadays'.

In order to think about these issues, we elaborated on some concepts and ideas proposed by Jenkins, Green and Ford (2014) on their idea of propagability. This perspective presupposes the idea that "the process of content circulation generates meaning and adds value to the content that makes up current media. A fundamental idea for thinking about communication mediums in general, particularly virtual ones, is that if something does not propagate itself, it is dead, without existence" (Jenkins et al., 2014, p. 23).

The idea that content which is produced but not propagated on the network, or even on old broadcasting, is destined to fail, is an essential question for managers of public entities such as the RTP and the EBC. In an environment where the concept of propagability is related to the capacity that public broadcasting entities have for promoting online consumption of their content, one of the major challenges being faced is obtaining and maintaining a satisfactory audience level, that is, having an online presence and the ability to get noticed in an environment by circulating content that generates online users' interest. It is important for this analysis to consider that the RTP and EBC are two big public bodies that have existed and will continue to exist together over a significant amount of time.

The first public body is a broadcaster which uses traditional broadcasting channels like open television and radio stations. The other public body works with information technology and convergence. Both public bodies work with this technology, their administrative and managerial spaces almost always defined by multimedia. However, the development of multimedia and principally the development stage of activities within it differ in the RTP and EBC. Each one has its own history and internal workings arising from the ease and difficulty of managing and budgeting.

In a communication world of growing propagability, the multimedia area of public bodies needs to expand, articulate, and be sustainable and vigorous to ensure that they do not miss the virtual train. The development in information technology and the knowledge set that this segment could generate goes beyond the working dynamics of tools such as applications. It should generate a body of knowledge for the entity to understand

\footnotetext{
' This change is verified by data collected from the study carried out by the technology consulting company Accenture in 13 countries which indicated that $77 \%$ of internet users in Brazil access the net on mobile devices. Retrieved from http:// exame.abril.com.br/tecnologia/noticias/africa-do-sul-e-brasil-lideram-acesso-a-internet-movel.
} 
the technological and virtual changes, foresee changes and recognize - as much as possible - the many contemporary virtual audiences. This operational dimension should be a sample of "digital/virtual conscience", that is to say, a company's privileged segment that accumulates knowledge on propagating messages across the digital media universe and, especially, acquires the capacity to elaborate action plans for production and distribution of content virtually and to their users.

The perspective of propagability proposes a set of fundamental questions about how digital technical resources facilitate the circulation of some content in comparison to others, like how economic structures sustain or restrict this circulation, even the characteristics that make media texts interesting to a group and make them want to share the material across social networks of consumption and information sharing (Jenkins et al., 2014). The authors state that establishing a virtual participative culture based on the idea that diverse communities which collaborate through networks have roles and promote forms for circulating media content through this action and the projected adjustments these channels must make. With this, the public gets a much more representative meaning for circulated content than on traditional broadcasting. This makes certain producers and corporate communicators pay more attention to the needs of online users and understand what they want in order to produce content that meets the specific demands of online users.

\section{The ANALYSIS}

In order to analyze the challenges that managers of public broadcasting entities feel are more important for their online development, it was necessary to read up on how these institutions are currently carrying out their digital/virtual actions. For this, we analyzed how these actions are being implemented on the EBC (www.ebc.com.br) and RTP (www.rtp.pt) portals between September and October of 2015. Our analysis is therefore based on research on the convergence level in these entities and how they must adapt their portals to its use, format, languages and media content distribution ${ }^{2}$. We then conducted interviews with professionals ${ }^{3}$ from each public entity whose job it is to develop and implement mechanisms for producing and distributing media content.

This has led us to believe that both portals give a fairly good indication of how institutions and their managers are adapting to new digital technology and, to a larger degree, how important they feel these new innovations are to the development and survival of their public broadcasting channels. Based on the data, we looked at these institutions from two fronts: early convergence at EBC and the changing convergence at RTP.

\footnotetext{
${ }^{2}$ To guide our observation we considered the following analysis categories: a) if the portal had integrated traditional radio and television products; b) if there was on demand content service; $c$ ) if there was real time content on offer; d) the multimedia language used; e) adoption of transmedia strategies; $f$ ) the use of archived material; $g$ ) if there were proposals to engage the audience with mechanisms and used strategies; h) social network participation and strategies; i) creating an audience community; j) creation/distribution of mobile device applications; I) developing products to connect traditional media with the internet like games or events.

${ }^{3}$ The person interviewed at the EBC was Denize Bacoccina, the Executive Superintendent of Agencies and Digital Content. At RTP, Multimedia Director, João Pedro Galveias, was interviewed.
} 


\section{THE EBC: FARLY CONVERGENCE}

In general, the EBC portal is an example of convergence in its initial stage as compared to the available technologies used by other similar entities. First is the architecture. The portal pages were structured for specific news agency, radio, television and company ombudsman sites to access and to send users to informative/thematic areas deemed important by the EBC. The portal was based on a traditional concept: separating channels even though they coexist in the same space. Separating the radio, TV and agency services indicates a low level of convergence.

The company's strategy was to solidify the EBC's name as it was practically unknown to the general public. Two projects were developed for the portal in less than 4 years. The first project, between 2012 and 2013, focused on drawing attention to the news on the agency's home page instead of just broadcasting on TV Brasil and radio. Soon after the portal was released, the company faced the problem of restricted content distribution. Only half of the TV schedule was produced by the company itself, so the other half was coproduced, the contract for which did not have a clause stating web use, which made it almost impossible to be seen on other platforms.

In 2014, the portal underwent a technical and visual restructuring to make it more responsive by using a flexible design to automatically adapt to any device (PC, cellular, tablets, etc.). The new phase was still being implemented in September 2015; its radio and TV pages were being restructured. However, this separation still remained between the channels and the goal of becoming a portal with news mainly produced by the Brazil Agency ${ }^{4}$. The radio and TV channels were still absent from the EBC's home page. Users could only listen to live radio broadcasts controlled by the company because TV Brasil, an open source channel transmitted across the country, was not streaming its programming at the time. Only the international TV Brasil was being transmitted across Web TV.

Another aspect is the low amount of on demand content which could increase the range of many products like television series, fiction, children's programs, radio programs and more. The problem was in part related to not having any image. However, there was not much audio or video news material being handed in that was integrated with text or images ${ }^{5}$. A few multimedia initiatives had been developed and were available in the section "Special Content". Even though producing special content was a commendable effort, it was far from being broadcast across multiple media channels, each one giving understanding to a theme or issue. There is no doubt that the production achieves some level of crossmedia, but overall it is not effective because it means reproducing various media content in the same place without necessarily adapting it.

In terms of public interaction and participation, the EBC has institutional pages on social networks and only a few radio and television programs had specific pages on social networks for audiences to leave comments.

\footnotetext{
${ }_{4}^{4}$ The Brazil Agency is a national news publisher for the EBC whose daily content can be repeated for free in newspapers and radio and TV stations in the interior of the country.

5 The low level of media integration was explained by the company's technical limitations which did not have the Content Delivery Network (CDN) tool; a distribution network of multimedia content. Without this network, the company would have to manually convert the videos into many formats for a number of mobile devices.
} 
The company is even more behind when it comes to applications for mobile devices like tablets or smartphones. Only radio stations have applications for listening to live programs. The application offers no other type of information or content. There has been no attempt to include games or promote events related to the content on the EBC's television and radio stations.

With the exception of a few programs whose pages come close to having multimedia language, the portal as a whole - the structure, texts, graphics and visual - is of an informative nature. From our point of view, it identifies itself as more of a news agency characterized by hard news coverage mainly of facts which have already been released on other news portals. It tries to differentiate itself by covering issues like culture, education, environment and citizenship. Yet, this is difference is not really reflected in its coverage. It rarely offers in-depth coverage of material and is rarely complemented with multimedia resources. The low level of attractiveness prevents it from becoming a space for quality entertainment and information and therefore meets only a few of its objectives as a public service provider.

\section{Challenges for the EBC}

Given this situation, the manager of the EBC believes that the entity is still "crawling" through the process of technological modernization and preparation for occupying virtual space. This perspective is the result of the institution's history, created a little more than eight years ago and still fighting to establish and consolidate itself as a public broadcaster.

Despite a set of structural difficulties, this public entity has been adopting measures over the last few years for updating its portal in order to increase its accessibility and offer content produced by its broadcasting channels. The person responsible for multimedia at EBC confirms that the biggest challenge is administrating the complex process of modernizing the entity's virtual equipment because they do not have the available resources for realizing all the wide range of actions necessary for the company to have a satisfactory online presence. What it is looking for is to better administrate what the manager calls a "possible strategy"; the need to establish a list of priorities for the EBC to have a positive online presence.

In order for this to occur, the sector has been trying to obtain the financial resources necessary to ensure a minimum level of portal modernization and been making the efforts to further its plans and actions for the EBC to operate online. The manager believes that is necessary to establish administrative policies that clearly define the steps and responsibilities needed for updating as well as having a clear plan of who does what in the process. It is therefore essential that she institutionalizes one sector and designates a stable team of professionals ${ }^{6}$ for producing content and information technology who can develop a body of knowledge and understanding of the area which can be used to improve the company's digital/virtual strategies and performance.

\footnotetext{
${ }^{6}$ The EBC had up to 20 professionals working on IT developments. At the time of the interview, the manager stated that only three professionals were committed to their tasks in the sector.
} 
Another structural challenge is developing applications for the entity. The EBC believes it is far behind in this and still does not have applications that are widely available to the public. Searching for these resources is an uphill battle right now because, according to the manager, the institution already understands the importance of developing these technological resources given the large increase in mobile device use in Brazil and the world in general. Its biggest obstacle here is not the lack of vision but the financial and operational difficulties to put it in motion.

The manager points to another important goal which is managing to establish a working procedure within this new production environment with clear, coherent, realistic and measurable objectives. After recognizing the company's existing structural problems, she states that the EBC is still not ready to establish long term goals. The institution still does not have a clear definition of the objectives and steps it needs to take, or even how they would be done. There is a huge challenge behind analyzing a more complex context, overcoming bureaucratic red tape and defining goals in a dynamic environment where three, four or five years is a long time due to the speed at which the virtual world operates.

Another challenge facing the entity is the technology and the concept behind thinking and rethinking - or reshaping - its current portal. It was initially designed as a hub for converging content elaborated by both professionals within the company and external collaborators the entity maintained relations with. The result of this was a portal comprised of isolated areas dedicated to delivering content designed by the company's own radio, television and news agency.

Another reason this happened is the fact that the EBC always thought of the news content on its site as being a privilege. According to the manager "news is the most privileged thing the EBC has and it is a fundamental part of its mission as a public entity". The Brazil Agency has always been a strong brand of the EBC, recognized as "its own medium" inside the entity, different than other mediums, which is where the site gained its perspective on information and news it holds today. The manager believes that another factor influencing the preponderance of news on the site is the fact that the entity's mediums have to offer hard news as part of their daily programming. However, the challenge that is presented here, given her definition of the situation as "news being privileged", is one of thinking about how the institution will transform this predominance of informative content so that other content produced by the EBC may be included on the portal and be in demand by certain segments of the public.

It is important that thought goes into reconsidering the conceptual bases that regulate and establish parameters for defining the importance of news content and entertainment which the EBC produces and which guides it towards accomplishing its mission. The entity and its "critical professional mass" should see and understand how the flow of information, both in producing it and delivering it, is changing. The flow of information and accessing content do not occur by simply visiting a portal anymore, it occurs because there is interest on the part of users to access varied content.

What is important is the content and the ability to make platforms accessible online and not just accessible on institutions' home sites. It also shows that the importance 
does not only lie in producing content but also to be able to deliver this content to the public and the channels. For the manager, the main reason for reconsidering this process has to be elaborating a portal that goes beyond the current stage of offering fragmented virtual content without any specific format or language. She believes the challenge is in choosing the content for the WEB wisely.

The manager of the EBC admits that another huge challenge for the institution is elaborating a system for collecting and evaluating data on how users are using the EBC portal. In her opinion it is extremely important to gather and understand a representative quantity of information not only of a quantitative nature, but also a qualitative nature of the interests and wishes that drive users to networks, especially to access the EBC portal. This information will be important for generating knowledge and reading that will collaborate towards establishing guidelines for producing and offering content to the public. She states that basic information about their user is already being collected, albeit limited, and it has led to significant results in improved distribution of the institution's content to the public; the number of monthly visitors increased from 100 thousand to a little more than two million.

Another challenge of a technical nature still needs to be addressed which is making the whole site responsive ${ }^{7}$, in other words, capable of being accessed by mobile devices, for example, cellular phones. She said that the EBC site was transformed in response only to the environment dedicated for "privileged" news. Now there is the need to provide this technology to other content in order to improve the access quality and expand its possibilities because users who want to visit the non-responsive sites are still directed to the old parts of the portal, lowering the quality of access offered to users. It is a challenge that must be faced as a result of few resources.

Another challenge is promoting a change in the professional culture of certain areas within the entity, stimulating actions and ideas that encourage interactive content production. Since the creation of the multimedia section in 2014, the challenge has been in innovating the in-house professionals' perspective for their actual areas and their relation with the virtual environment, which could be the portal's ultimate goal, overcoming the segmentation of existing functions. For this to occur, the professionals need to be united so that they can open their minds to the fact that public mediums are a place that offers innovative content. Innovations in content production require professionals to have many production skills which professionals have had some struggles with and, as a consequence, the company too. The manager states that technicians, broadcasters and journalists all need to change the way they view the legal limits established for their practice and overcome the class-based and corporate resistance within the workplace.

She continues to defend that the company sets a sustainable training policy that trains professionals in various areas so that they are prepared to work in a diversified manner. She defends the need to create groups of young professionals with new ideas and creative freedom in order to establish a space for studying, creating and experimenting new

7 It is a technical solution for programming a site so that the elements that make it up automatically adapt to the screen size of the mobile device being used. 
languages used in content formatting. She believes these groups could potentially create more effective strategies for producing EBC content directed towards a younger public.

Finally, she states that one of the more important challenges the EBC faces is being able to speed up administrative, judicial and production processes so that they are reasonably compatible and effective for dealing with the continued demand of the virtual world and not get left behind by the speed of technology which would make for a shaky and sluggish operation.

\section{RTP: CONVERGENCE IN PROGRESS}

The RTP portal's characteristics demonstrate it is has much more consolidated convergence strategies behind its production. Good applications for mobile devices, structural logic, its design and editorial policies are its converging principles. It offers live access to programs on traditional broadcasting channels, allows you to personalize access by preferred content, has a number of other sites available on its portal which expands the information and entertainment to include other areas such as documentaries, dramas and program files, among others. It is clear that the home page is, in fact, well thought out in terms of structure, which transforms it into a showcase for content and mediums which can be explored immediately and quickly at the user's whim.

Some of the content has already been formatted for the Internet even though it came from traditional RTP mediums, demonstrated by the special materials available on the portal. It also uses an extensive amount of historical and audiovisual material that the entity keeps archived. It is obvious that in order to offer comprehensive, varied and dynamic content one must capture the audience's attention by using a series of catch phrases that act as "bait" in order to identify, in some form, the particular interests and wishes for entertainment and information that users have, the content that the portal offers and provide full access to on demand video and audio content.

The comments generated by the public on pages dedicated to radio and television programs have not yet resulted in any collaboration to provide more detail about the products in question. Most of the spaces provide forms of participation on social networks - only comments - and the portal clearly offers access to parts of the programs or the entire program. There is no sign that more active public participation on the sites that people most like is being worked on. There is still no consistent effort (as there is on public entity sites in Europe) to form a community of listeners or viewers who would be able to participate in a number of content and character-related activities from the series and programs they enjoy. Even still, this more active contact with the public is noticeable at RTP, even if on a lesser scale, in the applications created in which the public participate directly with programs, in real time, and make contacts with the other audience members as used in the program, The Voice Portugal.

The RTP portal already has features which are typical of convergence. It already uses different languages and formats to present content, offers design and a good amount of dynamic and interactive navigation. More than technical progress and expressing 
convergence, the portal is focused on strategies to adapt to the constant innovations on the Internet, developing more and more capacity to integrate content produced on its traditional media forms to digital ones, reinventing and creating new formats and languages for its content. This process is most certainly building innovative and creative forms for the RTP to realize its virtual audience potential.

\section{Challenges for The RTP}

According to the director of multimedia at RTP, the entity has been performing actions in this sector over the last 25 years. Over the course of two decades, the RTP went through numerous development stages in multimedia marked by institutional crises, budget limitations and changes to the internal layout of the entity8. In 2006, this layout, after going through various situations, determined a specific sector within the entity for deliberating and elaborating on multimedia content offered on its internet portal.

The set of challenges is wide and characterized by actions for organizing and institutionalizing the sector at RTP that takes care of its digital/virtual production. The multimedia manager states that an entity the size of the RTP and has as many sectors as it does needs to establish a board of directors to focus on and manage the production of multimedia content. On the other hand, this kind of action will tend to remain fragmented, dispersed and outdated. In his opinion, maintaining a specific sector for online production is the best way to integrate the various sectors which could collaborate and elaborate on internet products. He believes that the entity and its professionals should be conscientious and work in a new "multimedia ecosystem" which is increasingly impacting and affecting everyone, including the actual professionals working in communication and their daily production.

The RTP should be prepared to use its traditional production resources like radio and television for elaborating content for this new third sector which could bring together all the basic language elements from the other mediums. There is an understanding among directors and professionals at RTP, as occurs in other private communication mediums, that the product being offered to the public on the network is, and should be, much more than a television or radio program.

The manager defends the idea for creating projects that stimulate creativity towards building new platforms that the portal can distribute. He gives the example of bringing together young journalism or entertainment professionals to work on new proposals for content and new ways of distributing them to the public. These new professionals know and work within these environments with more ease. However, he points out that it is necessary for professionals to be mindful of technology that makes using resources easier. The professionals should not confuse their skills for using resources with specific technical knowledge. This would just be simplifying the technological challenge which

\footnotetext{
${ }^{8}$ When analyzing the challenges faced by the RTP, it is important to remember that over the last few years the entity has faced a more favorable financial situation after adopting the Audiovisual Contribution which citizens fund through their electricity bills. These resources provided the institution with more stable conditions to establish a realistic and viable plan for maintaining and developing in the new virtual media world.
} 
presents itself to the professionals in the sector. You must be conscious of the fact that being an advanced user does not always mean the professional will know exactly how to create virtual resources. Using resources is one thing, knowing how to do it on a professional level is another. The reason behind this position is the idea that an institutional culture must be established in order to create and experiment, leaving room for mistakes and the uncertainty of success.

An important challenge for the RTP here is to maintain, over time, a stable group of multimedia directors within the administrative structure. Maintaining this sector is important for a) establishing new product designs out of studies and experiments; b) obtaining a level of editorial freedom to prepare these materials which have been disconnected from other traditional sectors in the entity; c) developing a team of workers who have and can develop the specific skills for producing content and also for developing technology that keeps the portal operational and optimizes the development of systems that will distribute innovative and interactive content to users.

The manager of the RTP believes the institution is still forming and preparing teams to elaborate products for multimedia content. In his opinion, they are slowly developing actions on two fronts: one for developing technical resources for the institution and for training its professionals to use them effectively, competently and creatively; the other is an institutional structure to ensure that the work routines being put in place are longlasting ones. The challenge lies in creating a production programming unit within this segment, in other words, places where all the technical skills from all the entity's channels are brought together to meet the demands that multimedia production presents. He goes on to say that the content is decided on at the beginning because the professionals who work with multimedia must have the ability to produce various digital formats/languages.

Another important challenge is guaranteeing that there are resources laid out in the entity's budget to meet what he calls "creating a new media"; an action he defined as being the RTP's mission. As he sees it, there are two courses of action need to be developed in the public body: one to elaborate on the current media, and the other to think about the media of the future. This is a challenge because the products have to be for a diverse public. He gives an example of current professionals in media need to deal with the fact that the enormous impact the "television phenomena" has on audiences is becoming increasingly rare for the younger public. Due to the intense use of mobile devices and virtual environments, the challenge will be in elaborating a production model that produces cheaper content and has less of an impact on audiences, contrary to the prevailing model in traditional broadcasting. That is why he believes that the entity must offer traditional media to the public in the generic form yet at the same time have the obligation of governing their actions through innovation, offering new media content on the network to this same public.

The manager of the RTP states that the challenge is keeping the entity's multimedia sector in a "combat-ready position", in other words, making sure the entity does not lose sight of the work that has been done in this sector. The strategy is to promote a process that continually repeats the existence and presence of a sector and the contents it 
elaborates. This is a real fight for visibility for the sector. This is considered an important way to fight against and deal with the massive disproportion that exists between traditional broadcasting and digital/virtual. In order to have an idea of what he is talking about, he states that the institution's multimedia unit has a little more than 20 professionals working for it, and not all in the RTP framework, out of a total of a little less than 1700 employees9. His ideal number of people working in multimedia should be around 150.

Another challenge he pointed out is that sector's actions still do not have any level of institutionalization which would allow establishing short or medium term developmental goals or parameters. There is also no metric system for collecting the quantitative data of audiences and visits or qualitative information on users who search for the institution's portal, what they are looking for and their positions. This is an important challenge because composing and feeding a data bank that defines user profiles would make it possible to think and elaborate on a set of strategies to produce content that parts of the institution's public demand. The manager of the RTP confirms that in order to achieve this objective it would be necessary to provide resources for establishing technical, operational and professional structures to sustain the necessary research and technological developments. The manager believes this is the first and possible step to take to create user subscriptions for the entity's portal.

Lastly, he indicates the need to create a technical structure and have people to follow what happens on social networks and observe the trends that develop there. He states that there is no way to control or determine what will happen in these environments. The secret to being relevant in these universes is being able to think of and produce a good product which has some impact - propagability - and mainly generates user interest.

\section{Conclusion}

What we can see from speaking to the managers is that the challenges are large and require, on many fronts, the institutions to reinvent themselves in order to "keep their flags waving" in a territory so outlined and highly disputed for by the "network of networks". The interviews showed that the common perspective is that the main challenge to be faced is promoting a mental change within the public entities. It would require policies to be worked on and awareness of administrative structures by its directors and council members so that they were conscious and informed about changes going on in communication/broadcasting by incorporating and developing increasingly quick and intense digital information technology. Only through this clarification procedure and being aware of the potential the entities can achieve by acting on the internet will it be possible to become a sustainable institution of multimedia sectors, and the natural dispute for resources in an entity which has an obligation to offer information and entertainment to the public in two forms; by the traditional system of broadcasting or virtually.

This awareness is very useful and is considered fundamental towards implementing other changes. Making this a reality is highly complex due to the many changes that

\footnotetext{
${ }_{9}$ Data retrieved from http://www.atelevisao.com/rtp/rtp-volta-a-reduzir-numero-de-trabalhadores/.
} 
the virtual environment demands of institutions and their managing bodies. The changes should be in working order for both administrative duties and content production. Furthermore, it is of utmost importance that these changes produce real results in the constantly turbulent financial world of entities, ensuring budget resources for activities that the multimedia sectors must develop.

Another great challenge for managers is getting the entities to surpass the traditional broadcasting stage and its modi operandi and make a leap towards a new step while adding a renewed outlook and, consequently, reshaping their work methods, production methods and distribution methods which now design and elaborate convergence of informative products and entertainment directed to consumption in the virtual world.

In order for this to occur, the managers defend a position assumed by their sectors which is note in their structures and fight for promoting changes in strategic reading which these entities currently perform and the future of the public graduation, putting value on changes which have occurred in producing and formatting multimedia content and, especially, being attentive to the changes to the forms of consumption and access of these products.

Another important challenge is the culture change which must take place for professionals. The changes are broad and alter conceptions and work processes for elaborating content, even the perspective that the professionals themselves have of their skills, possibilities and performance limits. The managers made it clear in their interviews that the innovation, momentum and use of varied language resources (images, texts and sound) impose changes on professionals that clash with the older limits for skills and jobs performed by any particular professional. A professional who works in this area must overcome the compartmentalization of roles and produce audio and image without distinction. Put in another way, a multimedia producer has to be everything from photographer to reporter in order to produce audio or image materials.

Along these lines, it seems to us that the managers have been trying to think and, in particular, guarantee the creation and stable maintenance of departments and minimal teams of professionals to think about and administer the entity's relationship with its potential virtual public, following the momentum of this universe and collecting data that demonstrates the positions, criticism, praise, wishes and demands that audiences present and which can be used positively towards guiding public entities' production strategies as well as maximize distribution and knowledge of its products through the public who are online and use the network. Also meeting one of its objectives as a public institution; making itself available to as many people as possible.

It is in this scene of mutation that the EBC and the RTP need to act. Among its complex challenges, we believe that establishing a medium term virtual strategy is one of the most important ones broadcasting must face in the present and in the future. This set of actions could be a fundamental tool for institutions to distribute its brand and its products/content to certain segments of the public, in particular the younger public, who currently use very few traditional broadcasting channels. The managers' statements show that the entities need to fight against managerial, financial, operational, political and old 
professional cultural impossibilities from the institutions' own culture which end up resulting in distinct administrative and technical outlooks existing in these institutions, to overcome the insecurities and resistance which has traditionally marked the processes of innovation and transformation, just like the ones that affect broadcasting today.

Only facing each one of the scenes will the EBC and the RTP be able to change, incorporate and crystallize new parameters of production and new protocols to guide their work and media content for the virtual world. This could allow institutions to enhance their online presence and consequently gain significant returns in terms of representation and social legitimacy and for the survival of the public bodies analyzed in this article.

\section{BibliogRAPHIC REFERENCES}

Arons de Carvalho, A. (2009). A RTP e o serviço público de televisão. Coimbra: Edições Almedina.

Benvenido, L. (2012). La televisión ante el desafio de internet. Salamanca: Comunicación Social Ediciones y Publicaciones.

Bianco, N. R. D., Esch, C. E. \& Moreira, S. V. (2012) Radiodifusão pública: um desafio conceitual na América Latina. Estudos em Comunicação, 12, 155-181.

Bustamante, E., Franquet, R., García Levya, T., López, X. \& Pereira, Y. X. (2008). Alternativas en los médios de comunicación digitales - Televisión, rádio, prensa, revistas culturales y calidad de la democracia. Barcelona: Gedisa.

Bustamante, E. (2003). Hacia un nuevo sistema mundial de comunicación - Industrias culturales en la era digital. Barcelona: Gedisa.

Cardoso, G. (2007). A mídia na sociedade em rede. Rio de Janeiro: Editora FGV.

Coutinho, M. (2006). Movimentos de mudança política na América do Sul contemporânea. Revista de Sociologia e Política, 27, 107-123.

Fuenzalida, V. (1998). Situación de la televisión pública en América Latina. Felafacs - Diálogos de la comunicación, 53, 89-119.

Graván, M. L. (2012). El futuro de la televisión pública. La necesaria alianza con la ciudadanía. Madrid: Editorial Popular.

Jenkins, H. (2015). Cultura da convergência. São Paulo: Editora Aleph.

Jenkins, H., Green, J. \& Ford, S. (2014). Cultura da conexão - criando valor e significado por meio da mídia propagável. São Paulo: Editora Aleph.

Mateo Pérez, R. \& Bérges Saura, L. (2009). Los retos de las televisiones públicas: financiación, servicio público y libre Mercado. Sevilla: Comunicación Social Ediciones y Publicaciones.

Mendel, T. (2011). Serviço público de radiodifusão: um estudo de direito comparado. Brasília: UNESCO.

Moraes, D. (2009). A batalha da mídia - Governos progressistas e políticas de comunicação na América Latina e outros ensaios. Rio de Janeiro: Pão e Rosas.

Serra, P. (2015). A televisão ubíqua. Covilhã: UBI.

Wolton, D. (2006). Elogio do grande público: uma teoria crítica da televisão. São Paulo: Ática. 


\section{OTHER REFERENCES}

Unesco (2001). Public Broadcasting: Why? How?. Retrieved from http://unesdoc.unesco.org/ images/0012/001240/124058Eo.pdf

\section{Personal interviews}

Bacoccina, Denize (2015). Brasília, 28-08-2015.

Galveias, João Pedro (2015). Lisboa, 16-09-2015.

\section{FUNDING}

Academic work supported by the CAPES Foundation, in cooperation with CAPES/ FCT for post-doctoral internship at Minho University in Braga.

\section{BIOGRAPHICAL NOTES}

Carlos Eduardo Esch took a post-doctoral internship at Minho University. He has a PhD in Sociology and Communication Sciences from the Complutense University of Madrid. He is professor for the Faculty of Communication at the University of Brasilia $(\mathrm{UnB})$ and a professor of his Post-Graduation Program. He is a researcher in the Laboratory of Communication Policies at UnB (LAPCOM). He funded and coordinated the Latin American Public Radio Broadcasting Observatory at UnB.

Email: caduesch@hotmail.com

Universidade de Brasília

Programa de Pós-Graduação em Comunicação

ICC Norte, Bloco A, subsolo

Brasília-DF, 70910-900, Brasil

Mariana Martins de Carvalho has a PhD in Social Communication from the University of Brasilia (UnB) majoring in political and cultural communication with a focus on public communication. She is a researcher in the Laboratory of Communication Policies at UnB (LAPCOM). She is a Public Communication Manager for the Communication Company of Brazil.

Email: marimartins.pe@gmail.com

Empresa Brasil de Comunicação

Setor Comercial SUL - SCS Quadra o8 Bloco B-6o

$7^{\circ}$ Piso Inferior - Edifício Venâncio 2000 - Asa Sul

Brasília/DF, 70333-900, Brasil

* Submitted: 08-03-2016

* Accepted: 10-04-2016 